\title{
Pricing Policy in a Supply Chain: Negotiation or Posted Pricing
}

\author{
Chia-Wei Kuo \\ Department of Business Administration, National Taiwan University, Taipei, Taiwan, cwkuo@ntu.edu.tw \\ Hyun-Soo Ahn \\ Ross School of Business, University of Michigan, Ann Arbor, Michigan 48109, USA, hsahn@bus.umich.edu \\ Goker Aydin \\ Kelley School of Business, Indiana University, Bloomington, Indiana 47403, USA, ayding@indiana.edu
}

\begin{abstract}
$\mathrm{T}$ his article examines the choice of pricing policy (posted pricing or negotiation) toward end customers in a supply chain. Many retailers actively decide whether or not to encourage negotiation on the shop floor. Of course, the retailer's pricing policy influences not only the retailer's profit, but also the profits of the manufacturers who sell through the retailer. However, little is known about the forces that shape the pricing policy when two self-interested parties interact in a supply chain. We consider two alternative models depending on who has the power to decide the pricing policy: the manufacturer or the retailer. We find that an increase in the wholesale price weakens the retailer's ability to price discriminate through negotiation. Therefore, the retailer prefers negotiation at lower wholesale prices and posted pricing at higher wholesale prices. We also find that whenever the retailer prefers negotiation, the manufacturer does too. Therefore, the retailer's discretion over the pricing policy causes friction only when the retailer wants to use posted pricing, while the manufacturer wishes the retailer to use negotiation. We show that such friction arises only when product availability or the cost of negotiation is moderate. In this case, we show that the manufacturer may offer a substantial discount to persuade the retailer to negotiate. Surprisingly, in this region of friction, a decrease in the supply chain's capacity or an increase in negotiation costs (both of which are typically considered as worsening the retailer's business environment) translates into higher profit for the retailer.
\end{abstract}

Key words: supply-chain management; pricing; negotiation; retailing

History: Received: June 2010; Accepted: May 2012 by M. Eric Johnson, after 2 revisions.

\section{Introduction}

When it comes to deciding whether or not to allow negotiation on the shop floor, retailers do not necessarily default to the more commonly adopted format in their category. For example, in the automotive industry, where haggling is more or less the norm, Fiat and Scion dealers have nonetheless committed to selling at posted prices. Similarly, Crystal-Pierz, a chain of dealers selling power boats, advertises its "no haggle, no hassle" policy as a distinguishing feature. Some jewelers such as Tourneau (which operates both retail and online stores) and an online jewelry store, Melrose Jeweler (http://www.melrose.com), sell their luxury watches (e.g., Rolex) at posted prices even though negotiation is so common in jewelry that even some online stores allow their salespeople to negotiate with customers over the phone. Furthermore, these decisions are hardly ever cast in stone, and retailers revise their policies over time. For example, it was reported that a Home Depot store adopted an "entrepreneurial spirit" campaign, which empowered their salespeople to make deals with haggle-prone customers (Richtel 2008). Similarly, customers have been able to negotiate successfully at other primarily take-it-or-leave-it pricing stores such as Best Buy, Polo Ralph Lauren, and Nordstrom (Richtel 2008, Let's make a deal 2009). Conversely, Lithia Motors, the eighth-largest auto dealer chain in the United States, selling vehicles from all major manufacturers and brands (ranging from Porsche to General Motors to Toyota), announced in September 2007 that it would convert all of its 108 stores to haggle-free pricing within the next 3 years (Welch 2007).

Of course, a retailer's pricing policy for a productnegotiation vs. posted pricing-influences the manufacturer's bottom line as well. Therefore, it is not surprising that manufacturers attempt to influence the retailer's pricing policy. For example, no-haggle policies adopted by Scion and Fiat dealers have been practically imposed by Toyota (the owner of the Scion 
brand) and Chrysler (the US partner of Fiat). In fact, according to Laura Soave, the head of Fiat's American branch, dealers are asked not to offer deals below the manufacturer-suggested sticker price to eliminate the chance to haggle (LaBarre 2011). Likewise, it appears that the boat dealer Crystal-Pierz's no-haggle policy is driven by the manufacturer of Tracker boats, who insists that its products be sold at catalog prices. ${ }^{1}$

These examples establish that many retailers make a non-trivial choice between negotiation and posted pricing, and manufacturers have a stake in that choice. Motivated by these observations, we analyze which pricing policy emerges when there are two self-interested parties in the supply chain - the retailer and the manufacturer. To that end, we use a model that accommodates several features critical to the retailer's choice between negotiation and posted pricing, for example, the price-discrimination opportunities afforded to the retailer by the use of negotiation, the costs of negotiation incurred by the retailer and consumers, the supply-chain capacity of the product, and the manufacturer's ability to set the stage through its wholesale price. In the context of this model, we answer the following questions. What circumstances induce the retailer to favor posted pricing over negotiation and vice versa? Which pricing policy does the manufacturer prefer the retailer to use? When are the manufacturer and the retailer in conflict with regard to the choice of pricing policy? When a conflict exists, can the manufacturer utilize the terms of trade, for example, a simple and practical lever like the wholesale price, to induce the retailer to implement the manufacturer's desired pricing policy?

With regard to the retailer's preference, we find that an increase in wholesale price weakens the retailer's ability to price discriminate among customers through negotiation. Therefore, everything else being equal, negotiation dominates posted pricing at lower wholesale prices, and the opposite is true at higher wholesale prices. In addition, as intuition would suggest, the retailer prefers negotiation when the supplychain capacity is sufficiently high (i.e., when there is plenty of the product to go around) or the cost of negotiation is sufficiently low.

As for the manufacturer, we find that whenever the retailer gains more from using negotiation, the manufacturer also earns more from negotiation. Therefore, when the manufacturer and the retailer are in conflict, it is because the retailer wants to use posted pricing, but the manufacturer prefers the retailer to use negotiation. In this circumstance, the manufacturer will have to choose between two alternatives: either substantially discount the wholesale price so that the retailer opts for negotiation (an outcome which we refer to as reconciliatory negotiation) or force the retailer to switch to posted pricing with a higher wholesale price.

The cost of negotiation and supply-chain capacity critically affect whether the retailer and the manufacturer will find themselves in conflict over pricing policy applied to end consumers. Specifically, when supply-chain capacity is high or the cost of negotiation is low, both the manufacturer and the retailer want negotiation to be the pricing policy toward end customers. Hence, the supply chain settles into negotiation. Likewise, when the supply-chain capacity is low or the cost of negotiation is high, the supply chain naturally settles into posted pricing. However, when the supply-chain capacity or the cost of negotiation is moderate, the incentives of the manufacturer and the retailer are no longer aligned. This region is where the reconciliatory negotiation arises and the manufacturer sacrifices some of its margin to ensure that the retailer uses negotiation. It is in this region that counterintuitive phenomena occur. For example, an increase in negotiation costs or a decrease in capacity could translate into higher profits for the retailer, because the retailer's discretion over the pricing policy forces the manufacturer to offer a substantially lower wholesale price.

The rest of the article is organized as follows. We position our article with respect to the earlier literature in section 2. In section 3, we describe the model and present the preliminary results. Section 4 provides the analysis and results for the discretionary retailer model, in which the retailer is the party that chooses the pricing policy. For a brief comparison, in section 5 we present the results for the manufacturer leadership model, in which the manufacturer is able to dictate the retailer's pricing policy toward end consumers. Section 6 concludes the article. All proofs appear in the Online Appendix.

\section{Literature Review}

There are several articles that examine the trade-off between posted pricing and negotiation from the perspective of a single retailer. Riley and Zeckhauser (1983) show that when the seller incurs costs to bring new customers, posted pricing is better than negotiation. Wang (1995) and Arnold and Lippman (1998) compare the profits of posted pricing and negotiation when the retailer sells one object and find that bargaining is always preferable to posted pricing if the retailer's cost of negotiation or the expected bargaining power of buyers is sufficiently low. Roth et al. (2006) find that the retailer is more likely to adopt negotiation if the product is customizable. A number of articles consider the same question-posted pricing vs. negotiation-but in the presence of competing retailers. Bester (1993) considers competing retailers, 
all of whom collectively use either posted pricing or negotiation and characterizes the equilibrium under each pricing policy. Adachi (1999) considers the pricing policies of two competing retailers and finds that both retailers will use the same pricing policy in equilibrium. On the other hand, by allowing the market to consist of both bargainers and non-bargainers, Desai and Purohit (2004) show that both posted pricing and negotiation can coexist in equilibrium. In addition, they show that two types of prisoners' dilemma can occur: Even though both retailers would be better off by committing to posted pricing, both may use negotiation in equilibrium, and vice versa. In contrast to previous work, our article examines the retailer's choice of pricing policy in a supply chain where the self-interested manufacturer can influence the retailer's choice.

In our model, when the retailer adopts negotiation, a customer will buy at a transaction price according to the Generalized Nash Bargaining Solution (GNBS), which has been widely used in modeling the outcome of negotiation between the retailer and customer. For example, among the aforementioned articles that study the choice between posted pricing and negotiation, Arnold and Lippman (1998), Bester (1993), Desai and Purohit (2004), Roth et al. (2006), and Wang (1995) all use GNBS to model the negotiation outcome. When using negotiation, the retailer in our model must choose a cutoff price below which the product will not be sold. The transaction price is then determined by the cutoff price, the individual customer's valuation, each party's relative bargaining power, and the costs of negotiation incurred by both parties.

Our work is also related to the stream of research on trade promotions, that is, wholesale price discounts that the manufacturer offers to induce the retailer to lower its selling price. For example, Lal et al. (1996) consider a model where two identical manufacturers sell through a single retailer. Their customer population consists of three customers: one switcher and two loyals. In this model, trade promotions exist because the manufacturers compete for the switcher. Dreze and Bell (2003) consider a singleretailer, single-manufacturer setting. They compare the effects of two different contractual arrangements for trade promotions: wholesale price discounts vs. rebates paid to the retailer on units sold to the end consumer. Both in our work and the work on trade promotions, the manufacturer uses the wholesale price as a lever to influence the retailer's decision making. However, in the trade promotion literature, the retailer is assumed to use a posted pricing policy, while in our work the wholesale price affects the retailer's choice between posted pricing and negotiation.

There are several recent articles that analyze negotiation in the context of supply-chain management.
These include Dukes and Gal-Or (2003), Gurnani and Shi (2006), Iyer and Villas-Boas (2003), Lovejoy (2007), Nagarajan and Bassok (2008), and Wu (2004). For a review on cooperative bargaining in supply chains, see Nagarajan and Sosic (2008). Most of this work models negotiation between a supplier and a buyer who then meet the end-customer demand by selling at a posted price. In contrast, we examine the salesformat choice of the retailer, who may use posted pricing or negotiation when selling to the end customers, and we analyze how this choice can be influenced by the manufacturer whose profit also depends on the retailer's pricing policy.

\section{Model Description and Preliminaries}

We consider a supply chain comprised of one manufacturer and one retailer where the manufacturer produces a product at a unit cost $c$ and sells at a unit wholesale price, $w \geq c$. After the manufacturer determines the wholesale price, the supply chain commits to using one of two pricing policies toward end customers: posted pricing or negotiation. Under posted pricing, all customers who purchase will pay the same take-it-or-leave-it price. On the other hand, under negotiation, customers will pay individually negotiated prices. We consider two alternative models: one in which the retailer has discretion over the pricing policy and the other in which the manufacturer has the power to dictate the retailer's pricing policy.

After the pricing policy is determined, the retailer purchases from the manufacturer. However, the retailer's purchase quantity cannot exceed $Q$, which we refer to as the (supply-chain) capacity. The capacity, $Q$, determines the product's availability and admits multiple interpretations. For example, it could arise from the manufacturer's production capacity, or the retailer's storage space or working capital constraints, or a rationing policy imposed by the manufacturer.

We consider an infinitesimally divisible consumer population in which the consumers are heterogeneous in their valuation of the item. Let $a$ be the size of the consumer population and $\bar{F}(x):=1-F(x)$ represent the fraction of the consumers that value the product at $x$ or more. Then, $a \bar{F}(x)$ can be interpreted as the portion of the consumers with valuation $x$ or higher. We refer to $F(x)$ as the valuation distribution and denote its density by $f(x)$. All of the results hold under the following assumption on the valuation distribution, $F(\cdot)$.

Assumption 1. $F(\cdot)$ has an increasing failure rate (i.e., $\frac{f(x)}{\bar{F}(x)}$ is increasing in $\left.x\right)$, and its density $f(\cdot)$ is twice differentiable and satisfies the following condition: 


$$
f^{\prime}(x)\left(2 f^{\prime}(x) \bar{F}(x)+f^{2}(x)\right)-f^{\prime \prime}(x) f(x) \bar{F}(x) \geq 0 .
$$

As we discuss in more detail below, Assumption 1 allows a wide range of valuation distributions. The assumption ensures that both the retailer's and manufacturer's profit functions are well behaved. $^{2}$

Before we present our model where the choice of pricing policy is endogenous, we first examine the supply chain under posted pricing (in section 3.1) and under negotiation (in section 3.2).

\subsection{Supply Chain Under Posted Pricing}

Suppose the retailer uses posted pricing and picks the posted price $p$; then only customers with valuations $p$ or higher will buy the product. Thus, the aggregate demand at price $p$ is given by $D(p)=a \vec{F}(p)$. Assumption 1 allows a wide range of valuation distributions that induce many commonly used demand functions, including linear, log-linear, and logit. Table 1 lists several specific examples of the valuation distributions and their corresponding demand functions, covered by Assumption 1.

Given posted price $p$, wholesale price $w$, and supply-chain capacity $Q$, the retailer's and manufacturer's profits are

$$
\begin{aligned}
\Pi_{\mathrm{RP}}(p, w, Q) & =(p-w) \min \{D(p), Q\} \\
= & (p-w) \min \{a \bar{F}(p), Q\}, \text { and } \\
\Pi_{\mathrm{MP}}(w, p, Q) & =(w-c) \min \{D(p), Q\} \\
& =(w-c) \min \{a \bar{F}(p), Q\} .
\end{aligned}
$$

$D(\bar{p}(Q))=Q$. Notice that $\bar{p}(Q)$ does not exist when capacity $Q$ is sufficiently high. ${ }^{3}$ Note also that the retailer will not set the price below $\bar{p}(Q)$. Had the retailer set a price below $\bar{p}(Q)$, the retailer could increase the per-unit profit margin without changing the quantity sold. A standard argument shows that the retailer chooses either $p^{u}(w)$ or $\bar{p}(Q)$, whichever is larger. Hence, given a wholesale price $w$ and capacity $Q$, the retailer's optimal posted price, denoted by $p^{*}(w, Q)$, is $\max \left\{p^{u}(w), \bar{p}(Q)\right\}$.

Define the market-clearing wholesale price, denoted by $\bar{w}_{\mathrm{P}}(Q)$, as the wholesale price at which the retailer is indifferent between $p^{u}(w)$ and $\bar{p}(Q)$, that is ${ }^{4}$

$$
p^{u}\left(\bar{w}_{\mathrm{P}}(Q)\right)=\bar{p}(Q) .
$$

Notice the significance of $\bar{w}_{\mathrm{P}}(Q)$. For any $w \leq \bar{w}_{\mathrm{P}}(Q)$, the retailer's optimal posted price, $p^{*}(w, Q)$, is exactly the market-clearing price, $\bar{p}(Q)$ (as lowering the posted price any further will not increase the sales quantity). On the other hand, if the wholesale price $w$ exceeds the market-clearing wholesale price, $\bar{w}_{P}(Q)$, then it is not optimal for the retailer to sell out the capacity $Q$. In this case, the retailer's optimal posted price, $p^{*}(w, Q)$, is $p^{u}(w)$, the optimal price in a supply chain without a capacity constraint. In summary, $\bar{w}_{\mathrm{P}}(Q)$ is the highest wholesale price at which the retailer finds it optimal to clear the market. Thus, given wholesale price $w$, the retailer's induced profit function, that is, the retailer's profit function following the best response $p^{*}(w, Q)=\max \left\{p^{u}(w), \bar{p}(Q)\right\}$, is

$\Pi_{\mathrm{RP}}\left(p^{*}(w, Q), w, Q\right)= \begin{cases}\Pi_{\mathrm{RP}}(\bar{p}(Q), w, Q)=(\bar{p}(Q)-w) Q & \text { for } c \leq w \leq \bar{w}_{\mathrm{P}}(Q), \\ \Pi_{\mathrm{RP}}\left(p^{u}(w), w, Q\right)=a\left(p^{u}(w)-w\right) \bar{F}\left(p^{u}(w)\right) & \text { for } w \geq \max \left\{c, \bar{w}_{\mathrm{P}}(Q)\right\} .\end{cases}$

Define $p^{u}(w)$ as the posted price that optimizes the retailer's profit when the supply-chain capacity is not restricted, that is, $p^{u}(w)=\arg \max _{p} \Pi_{\mathrm{RP}}(p, w, Q)$ with $Q \geq a$. For given capacity $Q$, let $\bar{p}(Q)$ be the marketclearing price at which demand equals capacity:

Table 1 Examples of Valuation Distributions and Corresponding Aggregate Demand Functions

\begin{tabular}{ll}
\hline Valuation distribution $F(p)$ & Aggregate demand $D(p)$ \\
\hline Uniform $\left[0, \frac{a}{b}\right): F(p)=\frac{p b}{a}$ & $a-b p$ (linear demand) \\
Exponential $(\lambda): F(p)=1-e^{-\lambda p}$ & $a e^{-\lambda p}$ (log-linear demand) \\
Weibull $(\alpha, \beta): F(p)=1-e^{-\left(\frac{\rho}{p}\right)^{\alpha}}$ & $a e^{-\left(\frac{p}{p}\right)^{\alpha}}$ \\
Difference of two Gumbel r.v.'s & $\frac{a e^{\alpha-p}}{1+e^{\alpha-p}}$ (logit demand) \\
(utilities of buying and not buying) with & \\
scale parameter 1 and means $\alpha$ and $0:$ & \\
$F(p)=\frac{1}{1+e^{\alpha-p}}$ & \\
\hline
\end{tabular}

Consider now the manufacturer's wholesale price decision: Anticipating the retailer's response, the manufacturer's profit under posted pricing is

$$
\begin{aligned}
& \Pi_{\mathrm{MP}}\left(w, p^{*}(w, Q), Q\right) \\
& \quad= \begin{cases}(w-c) Q & \text { for } c \leq w \leq \bar{w}_{\mathrm{P}}(Q), \\
a(w-c) \bar{F}\left(p^{u}(w)\right) & \text { for } w \geq \max \left\{c, \bar{w}_{\mathrm{P}}(Q)\right\} .\end{cases}
\end{aligned}
$$

The manufacturer chooses the wholesale price $w$ to maximize $\Pi_{\mathrm{MP}}\left(w, p^{*}(w, Q), Q\right)$. To this end, let $w_{\mathrm{P}}^{u}$ denote the manufacturer's optimal wholesale price in a supply chain without capacity restrictions, that is, $w_{\mathrm{P}}^{u}=\arg \max _{w} \Pi_{\mathrm{MP}}\left(w, p^{*}(w, Q), Q\right)$ when $Q \geq a$. Without a capacity constraint, $Q$, the manufacturer will choose $w_{\mathrm{P}}^{u}$. If the wholesale price $w_{\mathrm{P}}^{u}$ induces the retailer to sell less than the capacity $Q$, then $w_{\mathrm{P}}^{u}$ must 
be the optimal wholesale price for the manufacturer (as if there is no constraint on capacity). On the other hand, if the wholesale price $w_{\mathrm{P}}^{u}$ induces the retailer to sell out $Q$ units, then it is best for the manufacturer to set the wholesale price to $\bar{w}_{\mathrm{P}}(Q)$ as it is the largest wholesale price that induces the retailer to sell out the capacity. These observations are formalized in Proposition 1.

Proposition 1. Consider the supply chain under posted pricing. The manufacturer's optimal wholesale price is $w_{\mathrm{P}}^{*}(Q)=\max \left\{\bar{w}_{\mathrm{P}}(Q), w_{\mathrm{P}}^{u}\right\}$.

\subsection{Supply Chain Under Negotiation}

Suppose the retailer in the supply chain uses negotiation. Our negotiation outcome follows GNBS, which has been used to model the outcome of negotiation between a customer and the retailer (e.g., Bester 1993, Desai and Purohit 2004). Under GNBS, the total surplus is split between the two parties and its allocation to each depends on several factors: cost of negotiation, relative bargaining power, and disagreement payoffs (i.e., the payoff to each party when they fail to reach an agreement).

Negotiation takes time and effort on the part of both the retailer and the customer as each party learns about the price at which the other party is willing to buy or sell. For example, Welch (2007) reports that negotiation increases the need for additional sales managers at a car dealership, each of whom makes as much as $\$ 150,000$ per year in salary and compensation. The same article also reports that compared to dealers using haggle-free pricing, dealers using negotiation incur an additional $\$ 300$ in per-car advertisement costs. Customers also incur costs of negotiation. On average, customers spend about 4.5 hours to close a deal when purchasing a car (Welch 2007). The time spent and effort exerted by the customer and the retailer are captured in the form of negotiation costs in our model. Let $c_{r}$ and $c_{b}$ denote the cost of negotiation incurred by the retailer and customer, respectively.

Allocation of the surplus to each party also depends on their relative bargaining power. Following GNBS, we model the relative bargaining power by parameter $\beta \in(0,1)$. Let $\beta$ be the customer's relative bargaining power (thus, $1-\beta$ is the retailer's bargaining power) so that as $\beta$ approaches 1 , customers have all the bargaining power. Here, we assume $\beta$ to be the same across all customers. If we assumed an individual customer's $\beta$ to be drawn from a probability distribution (i.e., allowing consumers to have different bargaining power), all our results would continue to hold after replacing $\beta$ with its expected value.

An important construct in GNBS is each party's disagreement payoff as, at equilibrium, each party receives a disagreement payoff plus a portion of the remaining surplus according to their bargaining power. The customer's disagreement payoff is equal to the individual's utility of not purchasing, which is normalized to zero in our model. As for the retailer, let $p_{\min }$ be the disagreement payoff. Only customers whose valuations are high enough to cover the retailer's disagreement payoff will buy under GNBS, that is, the customers with valuation $r$ such that $r-c_{b} \geq p_{\min }$. As the disagreement payoff increases, the retailer will sell to fewer customers, but at higher prices. In our model, we allow the retailer to choose its disagreement payoff, $p_{\min }$, which is equivalent to choosing the range of customers to be served. Similar assumptions have been made by Wang (1995) and Arnold and Lippman (1998). A special case of our model is $p_{\min }=w+c_{r}$, in which case the retailer must sell to all customers who will pay at least the retailer's cost.

Once the retailer chooses its disagreement payoff, $p_{\min }$, GNBS stipulates that only the customers with valuation $p_{\min }+c_{b}$ and above will buy the item. If the final price is $p_{\mathrm{N}}$, a customer with valuation $r$ will obtain a surplus of $r-p_{\mathrm{N}}-c_{b}$; the retailer's (extra) surplus beyond its disagreement payoff $p_{\min }$ is $p_{\mathrm{N}}-p_{\min }$. Following the GNBS (Muthoo 1999), a consumer with valuation $r \geq p_{\min }+c_{b}$ and a retailer with the cutoff price $p_{\min } \geq w+c_{r}$ will agree on a transaction price $p_{\mathrm{N}}^{*}\left(p_{\min }, r\right)$ that maximizes the following objective function:

$$
\max _{p_{\mathrm{N}} \in\left[p_{\min }, r\right]}\left(r-p_{\mathrm{N}}-c_{b}\right)^{\beta}\left(p_{\mathrm{N}}-p_{\min }\right)^{1-\beta} .
$$

Note the significance of $\beta$, which represents the relative bargaining power of the consumer. If $\beta$ approaches 1 , any consumer with valuation $p_{\min }+c_{b}$ and above has all the bargaining power and extracts the entire surplus by paying the final price $p_{\mathrm{N}}^{*}\left(p_{\min }, r\right)=p_{\min }$. On the other hand, if $\beta$ approaches 0 , the retailer extracts the entire surplus by charging $p_{\mathrm{N}}^{*}\left(p_{\min }, r\right)=r-c_{b}$ to a consumer with valuation $r$. For any $\beta \in(0,1)$, the final price, $p_{\mathrm{N}}^{*}\left(p_{\min }, r\right)$, splits the surplus as follows:

$$
\begin{aligned}
p_{\mathrm{N}}^{*}\left(p_{\min }, r\right) & =\underset{p_{\mathrm{N}}}{\operatorname{argmax}}\left\{\left(r-p_{\mathrm{N}}-c_{b}\right)^{\beta}\left(p_{\mathrm{N}}-p_{\min }\right)^{1-\beta}\right\} \\
& =(1-\beta)\left(r-c_{b}\right)+\beta p_{\min } .
\end{aligned}
$$

Equation (8) can be rewritten as $p_{\mathrm{N}}^{*}\left(p_{\min }, r\right)=$ $p_{\min }+(1-\beta)\left(r-c_{b}-p_{\min }\right)$. The second term, $(1-\beta)\left(r-c_{b}-p_{\min }\right)$, represents the price premium that a customer pays on top of the retailer's disagreement payoff and captures the price discrimination benefits enabled by negotiation: The higher the 
customer's valuation, $r$, the higher the price premium. By choosing a higher $p_{\min }$, the retailer can increase the price paid by all customers who purchase, but the price discrimination benefits and the sales volume will decrease.

Given the retailer's disagreement payoff $p_{\min }$, the lowest valuation among the customers who buy is $p_{\min }+c_{b}$, which we denote by $q_{\min }$ and refer to as the cutoff valuation,

$$
q_{\min }:=p_{\min }+c_{b}
$$

Thus, choosing $p_{\min }$ is equivalent to choosing $q_{\min }$, and (8) can be rewritten as a function of $q_{\min }$ :

$$
p_{\mathrm{N}}^{*}\left(q_{\min }-c_{b}, r\right)=(1-\beta) r+\beta q_{\min }-c_{b} .
$$

Given a cutoff valuation $q_{\min }$, all customers with valuation $q_{\min }$ and above buy, yielding a total demand of $a \bar{F}\left(q_{\min }\right)$. Notice that the seller will never choose $q_{\text {min }}$ below the market-clearing price $\bar{p}(Q)$. If $q_{\min }$ were below $\bar{p}(Q)$, the retailer could always increase the cutoff valuation slightly, which would increase the transaction price $p_{\mathrm{N}}^{*}\left(q_{\min }-c_{b}, r\right)$ without changing the quantity sold, thereby improving the retailer's total profit. In addition, the retailer must choose the disagreement payoff, $p_{\min }$, so that it covers at least the wholesale price plus the retailer's cost of negotiation: $p_{\min } \geq w+c_{r}$. Consequently, the cutoff valuation $q_{\text {min }}$ must be at least as large as $w+c_{r}+c_{b}$.

For any $q_{\min } \geq \max \left[w+c_{r}+c_{b}, \bar{p}(Q)\right]$, the retail$\mathrm{er}^{\prime} \mathrm{s}$ and manufacturer's profits are given $\mathrm{by}^{5}$

$$
\begin{aligned}
& \Pi_{\mathrm{RN}}\left(q_{\min }, w, Q\right) \\
& \quad=a \int_{q_{\min }}^{\infty}\left[\left(p_{\mathrm{N}}^{*}\left(q_{\min }-c_{b}, x\right)-w-c_{r}\right)\right] f(x) d x \\
& \quad=a \int_{q_{\min }}^{\infty}\left[(1-\beta) x+\beta q_{\min }-w-c_{r}-c_{b}\right] f(x) d x, \text { and }
\end{aligned}
$$

$$
\Pi_{\mathrm{MN}}\left(w, q_{\min }, Q\right)=(w-c) a \bar{F}\left(q_{\min }\right)
$$

Define $q_{\min }^{u}(w)$ as the cutoff valuation that optimizes the retailer's profit when the supply-chain capacity is not restricted, that is, $q_{\min }^{u}(w)=$ arg $\max _{q_{\min }} \Pi_{\mathrm{RN}}\left(q_{\min }, w, Q\right)$ for $Q \geq a$. The retailer sets the cutoff valuation equal to either $q_{\min }^{u}(w)$ or $\bar{p}(Q)$, whichever is larger. Hence, given a wholesale price $w$ and capacity $Q$, the retailer's optimal cutoff valuation, denoted by $q_{\min }^{*}(w, Q)$, is $\max \left\{q_{\min }^{u}(w)\right.$, $\bar{p}(Q)\}$. As in the case of posted pricing, define the market-clearing wholesale price, denoted by $\bar{w}_{\mathrm{N}}(Q)$, as the wholesale price at which the retailer is indifferent between $q_{\min }^{u}(w)$ and $\bar{p}(Q)$, that is

$$
q_{\min }^{u}\left(\bar{w}_{\mathrm{N}}(Q)\right)=\bar{p}(Q) .
$$

The interpretation of the wholesale price $\bar{w}_{\mathrm{N}}(Q)$ is similar to that of its posted-pricing counterpart $\bar{w}_{\mathrm{P}}(Q)$ : Under negotiation, $\bar{w}_{\mathrm{N}}(Q)$ is the highest wholesale price at which the retailer finds it optimal to clear the market. ${ }^{6}$ Thus, given wholesale price $w$, the retailer's induced profit function, that is, the retailer's profit function following the best response $q_{\min }^{*}(w, Q)=\max \left\{q_{\min }^{u}(w), \bar{p}(Q)\right\}$, is

$$
\begin{aligned}
& \Pi_{\mathrm{RN}}\left(q_{\min }^{*}(w, Q), w, Q\right) \\
& = \begin{cases}\Pi_{\mathrm{RN}}(\bar{p}(Q), w, Q) & \text { for } c \leq w \leq \bar{w}_{\mathrm{N}}(Q), \\
\Pi_{\mathrm{RN}}\left(q_{\min }^{u}(w), w, Q\right) & \text { for } w \geq \max \left\{c, \bar{w}_{\mathrm{N}}(Q)\right\} .\end{cases}
\end{aligned}
$$

Consequently, the manufacturer's profit under negotiation is

$$
\begin{aligned}
& \Pi_{\mathrm{MN}}\left(w, q_{\min }^{*}(w, Q), Q\right) \\
& = \begin{cases}(w-c) Q & \text { for } c \leq w \leq \bar{w}_{\mathrm{N}}(Q), \\
(w-c) a \bar{F}\left(q_{\min }^{u}(w)\right) & \text { for } w \geq \max \left\{c, \bar{w}_{\mathrm{N}}(Q)\right\} .\end{cases}
\end{aligned}
$$

Anticipating the retailer's response, the manufacturer chooses the wholesale price $w$ to maximize $\Pi_{\mathrm{MN}}\left(w, q_{\min }^{*}(w, Q), Q\right)$. Let $w_{\mathrm{N}}^{u}$ denote the manufacturer's optimal wholesale price in a supply chain without any capacity restrictions, that is, $w_{\mathrm{N}}^{u}=$ $\arg \max _{w} \Pi_{\mathrm{MN}}\left(w, q_{\min }^{*}(w, Q), Q\right)$ for $Q \geq a$. Similar to the case of posted pricing, the manufacturer chooses either the market-clearing wholesale price or the wholesale price that will be chosen in the absence of a capacity constraint, as summarized in Proposition 2.

Proposition 2. Consider the supply chain under negotiation. The manufacturer's optimal wholesale price is $w_{\mathrm{N}}^{*}(Q)=\max \left\{\bar{w}_{\mathrm{N}}(Q), w_{\mathrm{N}}^{u}\right\}$.

The next proposition illuminates how the manufacturer's wholesale price and the ensuing cutoff valuation of the retailer depend on the costs of negotiation borne by both parties. To that end, define $c_{\mathrm{T}}=c_{r}+c_{b}$ to be the total cost of negotiation.

Proposition 3. Consider the supply chain under negotiation. The manufacturer's optimal wholesale price and the retailer's cutoff valuation depend only on the total cost of negotiation, $c_{\mathrm{T}}$. That is, for all $\left(c_{r}, c_{b}\right)$ such that $c_{r}+c_{b}=c_{\mathrm{T}}$ for some constant $c_{\mathrm{T}} \geq 0, w_{\mathrm{N}}^{*}(Q)$ and $q_{\min }^{*}\left(w_{\mathrm{N}}^{*}(Q), Q\right)$ remain the same.

To see the intuition behind Proposition 3, consider a negotiation between the retailer with the cutoff valuation $q_{\min }$ and a customer with valuation $r$, 
resulting in a transaction price $p_{\mathrm{N}}^{*}\left(q_{\min }-c_{b}, r\right)$. The retailer's margin is the transaction price, $p_{\mathrm{N}}^{*}\left(q_{\min }-c_{b}, r\right)$, minus the wholesale price, $w$, and the retailer's cost of negotiation, $c_{r}$. In addition, notice from Equation (10) that the transaction price, $p_{\mathrm{N}}^{*}\left(q_{\min }, r\right)$, is net of the customer's cost of negotiation, $c_{b}$, which implies that the retailer absorbs the customer's cost of negotiation as well. Thus, the retailer's margin depends only on the total cost of negotiation, not on how that cost is allocated between $c_{b}$ and $c_{r}$.

REMARK 1. Our discussion so far assumes that the customer's negotiation cost does not depend on his/ her reservation price. However, one could envision a situation where a customer with a higher valuation incurs a higher negotiation cost. All of our analyses and results go through even in this setting. Suppose that the negotiation cost borne by the customer with valuation $r$ is $c_{b}(r)=c_{b 0}+\alpha r, 0<\alpha<1$. Then, the GNBS (as defined in Equation (8)) now becomes $p_{\mathrm{N}}^{*}\left(p_{\min }, r\right)=(1-\beta)\left[(1-\alpha) r-c_{b 0}\right]+\beta p_{\min }$. After redefining $q_{\min }:=p_{\min }+c_{b 0}$, all subsequent results hold with $c_{\mathrm{T}}$ now given by $c_{r}+c_{b 0}$.

REMARK 2. All our results and insights extend to the case where negotiation attracts customers whose valuation for the product is lower than the valuation of those attracted by posted pricing. For example, suppose that when negotiation is used, a customer's valuation for the product, $r$, is scaled down to $\eta r$, where $0<\eta<1$. All our results will hold after modifying the transaction price so that $p_{\mathrm{N}}^{*}\left(p_{\min }, r\right)=$ $(1-\beta)\left(\eta r-c_{b}\right)+\beta p_{\min }$.

REMARK 3. Our negotiation model does not explicitly allow a list price from which the customers can negotiate down. However, adding such a feature to our model will not change the qualitative results and derived insights. If there exists an exogenously set list price, $p_{e}$ (capturing perhaps a quoted price from a competing retailer or a MSRP), this price will impose an upper bound on the final transaction price. In particular, the final transaction price for a customer with valuation $r$ will be $\min \left\{p_{\mathrm{N}}^{*}\left(p_{\min }, r\right), p_{e}\right\}$. Notice that for customers whose valuation is below $\frac{p_{e}-\beta p_{\min }}{1-\beta}+c_{b}$, the transaction price will be $p_{\mathrm{N}}^{*}\left(p_{\min }, r\right)$ and these customers will not be affected by the list price. On the other hand, customers with valuations exceeding $\frac{p_{e}-\beta p_{\min }}{1-\beta}+c_{b}$ will now pay $p_{e}$. Thus, negotiation still price discriminates based on customer valuation, but the revenue from high-valuation customers is now curbed by the list price, $p_{e}$. The list price will reduce the retailer's benefit from the negotiation, but we expect that our subsequent results will not change. In fact, if the list price is chosen by the negotiating retailer, the retailer will set the list price as high as possible so that it does not bind the benefit from negotiation, thus rendering the list price irrelevant. However, if one were to embellish our model so that the size of the consumer population (denoted by a) decreases in the announced list price, the retailer will face a new trade-off: a high list price will be a less oppressive bound for a final transaction price, but will also reduce the size of the market that the retailer serves. Such a role for the list price is beyond the scope of this article.

\subsection{Supply Chain with Endogenous Pricing Policy}

Sections 3.1 and 3.2 examine the supply chain when the pricing policy is fixed. Those preliminaries serve as building blocks for the model where the chain's pricing policy is a strategic decision, which we describe next. We consider two alternative models depending on who chooses the pricing policy. In the discretionary retailer model, the manufacturer sets the wholesale price, followed by the retailer choosing the pricing policy and the associated price (posted price or cutoff valuation). In the manufacturer leadership model, the manufacturer sets both the wholesale price and the pricing policy. In response to the manufacturer's decision, the retailer sets the associated price (posted price or cutoff valuation).

3.3.1. Discretionary Retailer Model. Given the manufacturer's wholesale price, $w$, the retailer's best response consists of the pricing policy and associated pricing decision: $p^{*}(w, Q)$ for posted pricing and $q_{\text {min }}^{*}(w, Q)$ for negotiation. Let $\mathcal{I}_{\mathrm{R}}$ be a binary variable that represents the retailer's decision on the pricing policy: $\mathcal{I}_{\mathrm{R}}=1$ if the retailer chooses posted pricing and $\mathcal{I}_{R}=0$ if the retailer chooses negotiation. Then, the retailer's best response is either $\left(\mathcal{I}_{\mathrm{R}}=1, p^{*}(w, Q)\right)$ or $\left(\mathcal{I}_{\mathrm{R}}=0, q_{\mathrm{min}}^{*}(w, Q)\right)$. For a given wholesale price $w$, the retailer solves the following problem: ${ }^{7}$

$$
\begin{aligned}
\max _{\mathcal{I}_{\mathrm{R}} \in\{0,1\}} & {\left[\mathcal{I}_{\mathrm{R}} \Pi_{\mathrm{RP}}\left(p^{*}(w, Q), w, Q\right)\right.} \\
& \left.+\left(1-\mathcal{I}_{\mathrm{R}}\right) \Pi_{\mathrm{RN}}\left(q_{\text {min }}^{*}(w, Q), w, Q\right)\right] .
\end{aligned}
$$

The manufacturer chooses its wholesale price anticipating the retailer's best response. Let $\mathcal{I}_{\mathrm{R}}^{*}(w, Q)$ denote the retailer's optimal pricing policy for given $w$ and $Q$. The manufacturer's problem is then

$$
\begin{aligned}
\max _{w \geq c} & {\left[\mathcal{I}_{\mathrm{R}}^{*}(w, Q) \Pi_{\mathrm{MP}}\left(w, p^{*}(w, Q), Q\right)\right.} \\
& \left.+\left(1-\mathcal{I}_{\mathrm{R}}^{*}(w, Q)\right) \Pi_{\mathrm{MN}}\left(w, q_{\min }^{*}(w, Q), Q\right)\right] .
\end{aligned}
$$

3.3.2. Manufacturer Leadership Model. Given the wholesale price, $w$, and the pricing policy 
chosen by the manufacturer, the retailer responds by choosing the price: $p^{*}(w, Q)$ if the manufacturer chooses posted pricing and $q_{\mathrm{min}}^{*}(w, Q)$ if the manufacturer chooses negotiation. Let $\mathcal{I}_{\mathrm{M}}$ be a binary variable that represents the manufacturer's decision on the pricing policy: $\mathcal{I}_{\mathrm{M}}=1$ if the manufacturer chooses posted pricing and $\mathcal{I}_{\mathrm{M}}=0$ if the manufacturer chooses negotiation. Then, the manufacturer's problem is

$$
\begin{aligned}
\max _{w \geq c, \mathcal{I}_{\mathrm{M}} \in\{0,1\}} & {\left[\mathcal{I}_{\mathrm{M}} \Pi_{\mathrm{MP}}\left(w, p^{*}(w, Q), Q\right)\right.} \\
& \left.+\left(1-\mathcal{I}_{\mathrm{M}}\right) \Pi_{\mathrm{MN}}\left(w, q_{\mathrm{min}}^{*}(w, Q), Q\right)\right] .
\end{aligned}
$$

We first present the results and discussion on the discretionary retailer model, followed by the manufacturer leadership model.

\section{Discretionary Retailer Model}

We first characterize the retailer's best response, represented by the pricing policy and the associated price, as a function of the manufacturer's wholesale price $w$.

Proposition 4 [RETAILER'S BeST RESPONSE]. There exists a threshold wholesale price $\hat{w}_{R}(Q)$ below which the retailer prefers negotiation and above which the retailer prefers posted pricing. ${ }^{8}$

Proposition 4 implies that once the retailer prefers posted pricing at a given wholesale price, then it continues to prefer posted pricing at all higher wholesale prices. To understand why, we first rewrite the retailer's profit function when the retailer uses negotiation, represented by Equation (11), with the optimal cutoff valuation $q_{\min }^{*}(w, Q)$ :

$$
\begin{aligned}
\Pi_{\mathrm{RN}}\left(q_{\min }^{*}(w, Q), w, Q\right) \\
=a \int_{q_{\min }^{*}(w, Q)}^{\infty}\left[q_{\min }^{*}(w, Q)-w-c_{\mathrm{T}}\right. \\
\left.\quad+(1-\beta)\left(x-q_{\min }^{*}(w, Q)\right)\right] f(x) d x \\
=a \bar{F}\left(q_{\min }^{*}(w, Q)\right)\left(q_{\min }^{*}(w, Q)-w-c_{\mathrm{T}}\right) \\
\quad+a(1-\beta) \int_{q_{\min }^{*}(w, Q)}^{\infty}\left(x-q_{\min }^{*}(w, Q)\right) f(x) d x .
\end{aligned}
$$

The first term in the equation above is equivalent to the expected profit under posted pricing when the posted price is $q_{\min }^{*}$ and the wholesale price is $w+c_{\mathrm{T}}$, leaving the retailer a unit margin of $q_{\min }^{*}-w-c_{\mathrm{T}}$. This term is always less than the profit that the retailer could obtain if it used posted pricing at the wholesale price $w$. Under negotiation, however, only the marginal customer (with valuation $q_{\mathrm{min}}^{*}$ ) yields a margin precisely equal to $q_{\min }^{*}-w-c_{\mathrm{T}}$, and customers with higher valuations yield higher margins. In fact, a customer with valuation $x>q_{\min }^{*}$ pays an additional $(1-\beta)\left(x-q_{\min }^{*}\right)$ on top of what the marginal customer pays. This price premium collected under negotiation is what the second term of Equation (19) captures. If the price premium collected under negotiation is sufficiently large, then the retailer would be better off under negotiation. Now note that, as the wholesale price $w$ increases, the cutoff valuation $q_{\mathrm{min}}^{*}$ increases as well. ${ }^{9}$ Hence, the price premium collected by the retailer diminishes at higher wholesale prices. This makes negotiation less attractive at higher wholesale prices, as suggested by Proposition 4 .

From Equation (19), we observe that the benefits from negotiation depend on the valuation distribution, in particular, the dispersion of the distribution. Observe that if all customers have the same willingness to pay, negotiation offers no value to the retailer. Hence, negotiation is more common in big-ticket items such as vehicles and diamond rings not simply because customers have high valuations for these products, but because customers have high degree of dispersion in their valuations.

Taking the retailer's best response into account, we now examine the manufacturer's problem of choosing the wholesale price. Proposition 5 examines the retailer's and the manufacturer's preferences toward the pricing policy.

Proposition 5. For any wholesale price at which the retailer prefers negotiation (i.e., $w \leq \hat{w}_{\mathrm{R}}(Q)$ ), the manufacturer also prefers negotiation.

One direct implication of Proposition 5 is that at the threshold wholesale price, $\hat{w}_{\mathrm{R}}(Q)$, which makes the retailer indifferent, the manufacturer is better off if the retailer uses negotiation. Hence, negotiation is the Pareto-optimal pricing policy when the wholesale price is $\hat{w}_{\mathrm{R}}(Q)$. Therefore, applying the Pareto-dominance criterion, the retailer chooses negotiation whenever $w=\hat{w}_{R}(Q)$. Such tie-breaking behavior on the part of the retailer can be easily enforced by choosing the wholesale price $\hat{w}_{\mathrm{R}}-\epsilon$ for arbitrarily small $\epsilon>0$ so that the retailer strictly prefers negotiation over posted pricing.

Recall that the manufacturer's profit is the margin $(w-c)$ times the sales quantity. Hence, Proposition 5 implies that, at the wholesale price where the retailer is indifferent between the two pricing policies, the manufacturer wishes the retailer to use negotiation, as it leads to a larger sales quantity. When the wholesale price is slightly above $\hat{w}_{\mathrm{R}}(Q)$, the manufacturer will continue to prefer that the retailer negotiate, but the retailer now prefers to use posted pricing. This implies that there is a range of wholesale prices above 
$\hat{w}_{R}(Q)$ where the manufacturer's and the retailer's preferences conflict. As we will see, this conflict of interest will have a critical effect on the pricing policy the supply chain eventually adopts.

Based on the structure of the best response established in Propositions 4 and 5, the manufacturer's problem of selecting the wholesale price, stated in Equation (17), can now be expressed as follows:

$$
\begin{gathered}
\max \left[\max _{c \leq w \leq \widehat{w}_{\mathrm{R}}(Q)} \Pi_{\mathrm{MN}}\left(w, q_{\min }^{*}(w, Q), Q\right),\right. \\
\left.\sup _{w>\widehat{w}_{\mathrm{R}}(Q)} \Pi_{\mathrm{MP}}\left(w, p^{*}(w, Q), Q\right)\right] .
\end{gathered}
$$

With the retailer's discretion in mind, the manufacturer determines a wholesale price to induce either negotiation (i.e., $w$ between $c$ and $\hat{w}_{R}(Q)$ ) or posted pricing (i.e., $w$ greater than $\hat{w}_{R}(Q)$ ). Notice that the manufacturer's wholesale price is driven by the tradeoff between the unit profit margin, $w-c$, and the sales volume: $a \bar{F}\left(p^{*}(w, Q)\right)$ under posted pricing or $a \bar{F}\left(q_{\min }^{*}(w, Q)\right)$ under negotiation.

Because lower wholesale prices are needed to induce negotiation, it becomes clear that the manufacturer will choose to induce negotiation by lowering the wholesale price only if negotiation leads to a sufficiently high sales volume compared to posted pricing. Proposition 6 describes the candidates for the manufacturer's optimal wholesale price and the resulting equilibria.

Proposition 6. The manufacturer's optimal wholesale price and the resultant equilibrium fall in one of the following three regimes:

(i) [Ordinary Negotiation] The manufacturer chooses the wholesale price $w_{\mathrm{N}}^{*}(Q)$ and the retailer uses negotiation with cutoff valuation $q_{\min }^{*}\left(w_{\mathrm{N}}^{*}(Q), Q\right)$.

(ii) [Reconciliatory Negotiation] The manufacturer chooses the wholesale price $\hat{w}_{\mathrm{R}}(Q)<w_{\mathrm{N}}^{*}(Q)$ and the retailer uses negotiation with cutoff valuation $q_{\min }^{*}\left(\hat{w}_{\mathrm{R}}(Q), Q\right)$.

(iii) [Posted Pricing] The manufacturer chooses the wholesale price $w_{\mathrm{P}}^{*}(Q)$ and the retailer uses posted pricing with price $p^{*}\left(w_{\mathrm{P}}^{*}(Q), Q\right)$.

In the ordinary negotiation regime, the wholesale price and the cutoff valuation are the same as those that would arise if the supply chain's pricing policy toward consumers were exogenously restricted to negotiation (analyzed in section 3.2). Likewise, in the posted pricing regime, the wholesale price and the posted price are the same as those when the supply chain's pricing policy toward consumers is exogenously restricted to posted pricing (analyzed in section 3.1). Proposition 6(ii), on the other hand, shows that there is a different type of negotiation equilibrium, which we refer to as reconciliatory negotiation. This equilibrium is a consequence of the retailer's discretion over pricing policy. It arises when the manufacturer prefers the retailer to negotiate, but cannot induce the retailer to do so at the wholesale price $w_{\mathrm{N}}^{*}(Q)$, which is the wholesale price the manufacturer would pick if it could mandate that negotiation be used. Facing a discretionary retailer, the manufacturer has to lower the wholesale price to $\hat{w}_{R}(Q)$ to induce negotiation. In other words, the manufacturer sacrifices some of the unit profit margin in exchange for the higher sales volume enabled by negotiation.

Which of these regimes will arise in equilibrium depends critically on the cost of negotiation. Proposition 7 characterizes how the equilibrium changes with respect to the total cost of negotiation, $c_{\mathrm{T}}$, when keeping everything else constant.

Proposition 7. There exist two thresholds, $c_{\mathrm{T}}$ and $\overline{c_{\mathrm{T}}}$, $c_{\mathrm{T}} \leq \overline{c_{\mathrm{T}}}$, such that the equilibrium pricing policy is ordinary negotiation for $c_{\mathrm{T}}<c_{\mathrm{T}}$, reconciliatory negotiation for $c_{\mathrm{T}} \in\left[\underline{c_{\mathrm{T}}}, \overline{c_{\mathrm{T}}}\right)$, and posted pricing for $c_{\mathrm{T}} \geq \overline{\overline{c_{\mathrm{T}}}}$.

The behavior described in Proposition 7 is illustrated in Figure 1. In this example, the supply-chain capacity $Q$ equals 500 , so that capacity never binds the sales quantity. When the total cost of negotiation is sufficiently low (i.e., $c_{T}<c_{T}$, with $c_{T} \approx 1.3$ in Figure 1), negotiation is preferred by both the retailer and the manufacturer. In such cases, the manufacturer can induce negotiation without sacrificing its profit margin. In contrast, as $c_{\mathrm{T}}$ increases, it becomes more costly for the retailer to use negotiation. However, as long as $c_{\mathrm{T}}$ is only moderately high, the manufacturer still prefers a negotiating retailer because it leads to a high sales volume. This is exactly what we observe in the middle region $\left(c_{\mathrm{T}} \leq c_{\mathrm{T}}<\overline{c_{\mathrm{T}}}\right.$, from approximately 1.3 to 1.575 in Figure 1), where the manufacturer voluntarily reduces the wholesale price to induce negotiation, resulting in a reconciliatory negotiation equilibrium. Finally, when $c_{T}$ becomes sufficiently large (i.e., $c_{\mathrm{T}} \geq \overline{c_{\mathrm{T}}}$, beyond 1.575 in Figure 1), the manufacturer no longer wishes to induce negotiation, either because the increase in sales volume does not make up for the necessary reduction in margin or because negotiation simply leads to lower sales volume due to the high negotiation costs. Of course, the specific values of the thresholds, ${\underline{c_{\mathrm{T}}}}_{\mathrm{T}}$ and $\overline{c_{\mathrm{T}}}$, depend on the valuation distribution of the product: The more dispersed the distribution, the more attractive negotiation becomes. Hence, these threshold values would increase. 
Figure 1 The Figure Illustrates the Sales Quantity (Left), the Wholesale Price and Posted Price or Cutoff Valuation (Center), and the Manufacturer's and Retailer's Profits (Right) in Equilibrium. Here, $a=500, \beta=0.3$, and $c=4$, and We Use Logit Demand with Valuation Distribution, $\boldsymbol{F}(\boldsymbol{x})=\frac{1}{1+\boldsymbol{e}^{20-x}}$

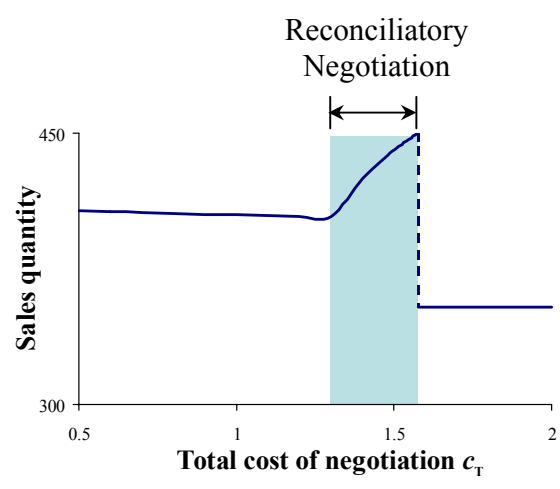

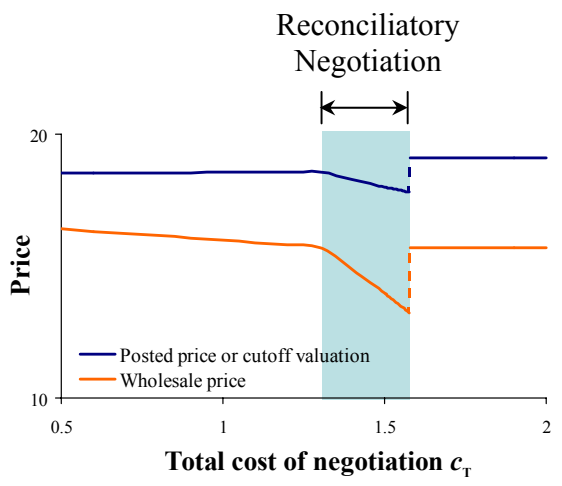

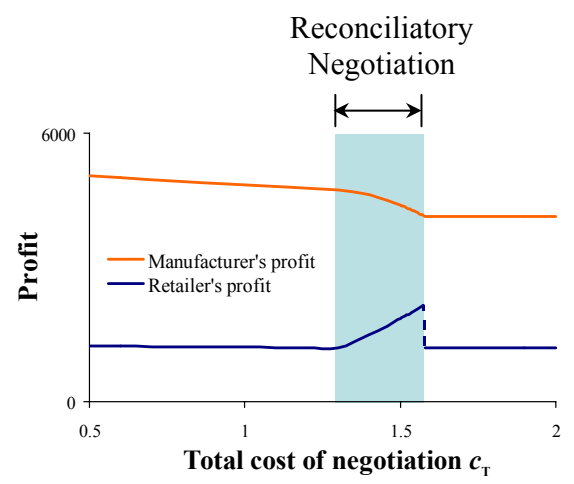

One implication of Proposition 7 is that the manufacturer may want to offer different wholesale prices to different retailers depending on the negotiation cost. The manufacturer can benefit from offering discounted wholesale prices to retailers with moderate negotiation costs, but not to those with high or low negotiation cost. Thus, heterogeneity in the negotiation costs of retailers may be yet another reason why manufacturers want to price discriminate among retailers.

Figure 1 demonstrates a surprising phenomenon: Under the reconciliatory negotiation regime, the retailer's profit and sales volume increase in the total cost of negotiation. In the regions where negotiation is used, the wholesale price decreases as $c_{\mathrm{T}}$ increases, implying that the manufacturer is absorbing some of the increased cost of negotiation. This reduction in wholesale price becomes more pronounced in the reconciliatory negotiation region. In fact, our analysis shows that, in the reconciliatory negotiation regime, a unit increase in the total cost of negotiation triggers a wholesale price reduction of more than one unit (see Lemma A.4(b) in Appendix A). In other words, the manufacturer more than compensates the retailer for the increase in the total negotiation cost, $c_{\mathrm{T}}$, so that negotiation remains as the chain's pricing policy toward consumers. This generous reduction in wholesale price explains why the retailer's profit and quantity sold increase in $c_{\mathrm{T}}$ under this regime.

Recall that the manufacturer's preference between negotiation and posted pricing is linked to the wholesale price and resultant sales volume. In particular, because negotiation is induced only at lower wholesale prices, the manufacturer prefers that the retailer use negotiation only when it leads to a significant increase in sales volume. If there is a limit on the supply chain's capacity (hence, the availability of the product), it can reduce the attractiveness of negotiation; thus posted pricing is more likely to emerge as the pricing policy toward consumers. To illustrate this, consider Figures 2 and 3, which illustrate the same example shown in Figure 1, but with more restrictive capacities, namely, $Q=406$ for Figure 2 and $Q=350$ for Figure 3. As Proposition 7 predicts, even with tighter capacity, equilibrium still moves from ordinary negotiation to reconciliatory negotiation to posted pricing as the cost of negotiation increases. Nonetheless, the tight capacity manifests

Figure 2 The Figure Illustrates the Sales Quantity (Left), the Wholesale Price and Posted Price or Cutoff Valuation (Center), and the Manufacturer's and Retailer's Profits (Right) in Equilibrium. Here, $a=500, \beta=0.3, c=4, Q=406$, and We Assume Logit Demand with Valuation Distribution $\boldsymbol{F}(\boldsymbol{x})=\frac{1}{1+e^{20-x}}$

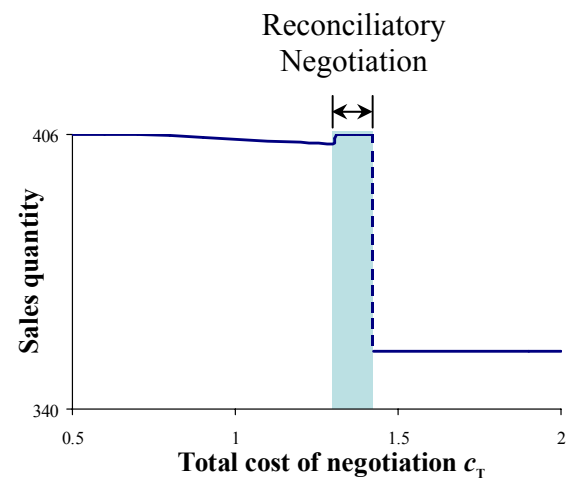

Reconciliatory

Negotiation

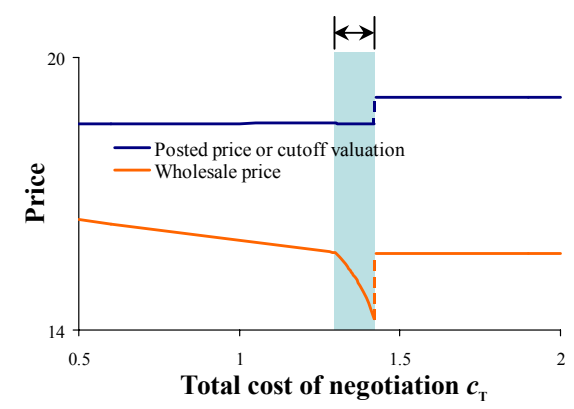

Reconciliatory

Negotiation

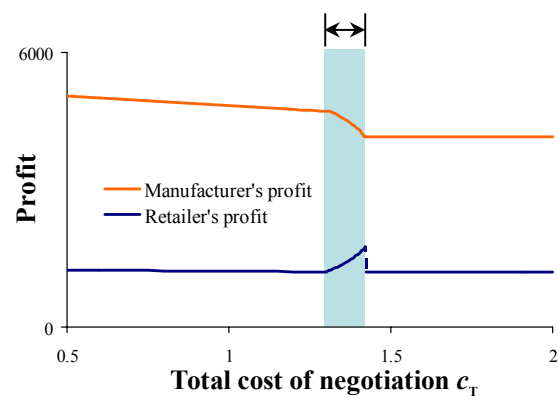


itself in both figures. In Figure 2, the capacity binds the equilibrium sales volume in two disjoint regions $\left(c_{\mathrm{T}}\right.$ between both 0.5 to 0.72 and 1.31 to 1.42 ); in Figure 3 , the capacity binds the sales volume at all levels of negotiation cost. Comparing Figures 1, 2, and 3, we notice that the range of negotiation cost in which posted pricing is the supply chain's pricing policy, expands as the capacity $Q$ becomes more restrictive: $c_{\mathrm{T}}$ above 1.575 in Figure 1, above 1.42 in Figure 2, and above 1.215 in Figure $3 .^{10}$ Proposition 8 formally characterizes the evolution of the supply chain's pricing policy toward consumers as a function of its capacity, keeping everything else constant.

Proposition 8. There exist two thresholds, $\underline{Q}$ and $\bar{Q}$, $0 \leq Q \leq \bar{Q} \leq \infty$, such that the equilibrium pricing policy is posted pricing for $Q<Q$, reconciliatory negotiation for $Q \in[\underline{Q}, \bar{Q})$, and ordinary negotiation for $Q \geq \bar{Q}$.

To explain the behavior described in Proposition 8, suppose that the equilibrium pricing policy is ordinary negotiation. As this supply chain's capacity decreases, the retailer will focus increasingly on selling to customers with higher valuations, resulting in a high cutoff valuation, which reduces the retailer's additional revenue enabled by price discrimination. Hence, as capacity decreases, posted pricing will become increasingly more attractive to the retailer. Given this preference of the retailer, the manufacturer will want to keep negotiation alive by offering a deeply discounted wholesale price, as long as the sales volume under negotiation is sufficiently higher than that under posted pricing. However, once the capacity becomes even tighter and more likely to bind the sales quantity, the manufacturer's benefit from negotiation begins to lose steam. Hence, the manufacturer charges a wholesale price that induces posted pricing.

The effect of supply-chain capacity may explain why Lexus dealers are willing to negotiate the LS series, but not willing to budge from the MSRP on the comparably priced SC series. In 2008, Toyota sold 20,255 units of the LS series, but only 1986 units of the SC series. ${ }^{11}$ To the extent that the sales volume is a proxy for the supply-chain capacity, these numbers indicate that the availability of the SC series is more limited than that of the LS series. According to our results, the limited availability could explain why Lexus dealers hardly negotiate on the price of the SC series. Prices of Toyota's Prius around 2006 provide further anecdotal evidence. According to a CNN.com article, $^{12}$ the availability of the Prius in the spring of 2006 was so tight that customers were paying more than MSRP for used Priuses with low mileage. Toyota's effort to increase production capacity, along with a lower vehicle demand during the recent economic crisis, made the Prius more available in 2009. Hence, at the time of writing, the average transaction price of a Prius is now well below the MSRP, ${ }^{13}$ which indicates that dealers are now given more room to negotiate.

Conventional wisdom suggests that the retailer's equilibrium profit will decrease as the capacity decreases. This is true whether the equilibrium pricing policy is ordinary negotiation or posted pricing. Surprisingly, this is not necessarily true under the reconciliatory negotiation equilibrium. Observe from the rightmost panel of Figure 4 that the retailer's profit increases as capacity decreases in the reconciliatory negotiation regime. This is perplexing as, in this example, the capacity is always exhausted in the equilibrium so the sales quantity will decrease as capacity decreases, but the retailer's profit increases anyway. This seemingly counterintuitive behavior can be understood by recalling that the manufacturer offers discounted wholesale prices in this regime. As capacity gets tighter, the retailer becomes more reluctant to use negotiation. The manufacturer counters by offering progressively lower wholesale prices, which is why the retailer's profit increases as capacity decreases.

Figure 3 The Figure Illustrates the Sales Quantity (Left), the Wholesale Price and Posted Price or Cutoff Valuation (Center), and the Manufacturer's and Retailer's Profits (Right) in Equilibrium. Here, $a=500, \beta=0.3, c=4, Q=350$, and We Assume Logit Demand with Valuation Distribution $\boldsymbol{F}(\boldsymbol{x})=\frac{1}{1+e^{20-x}}$
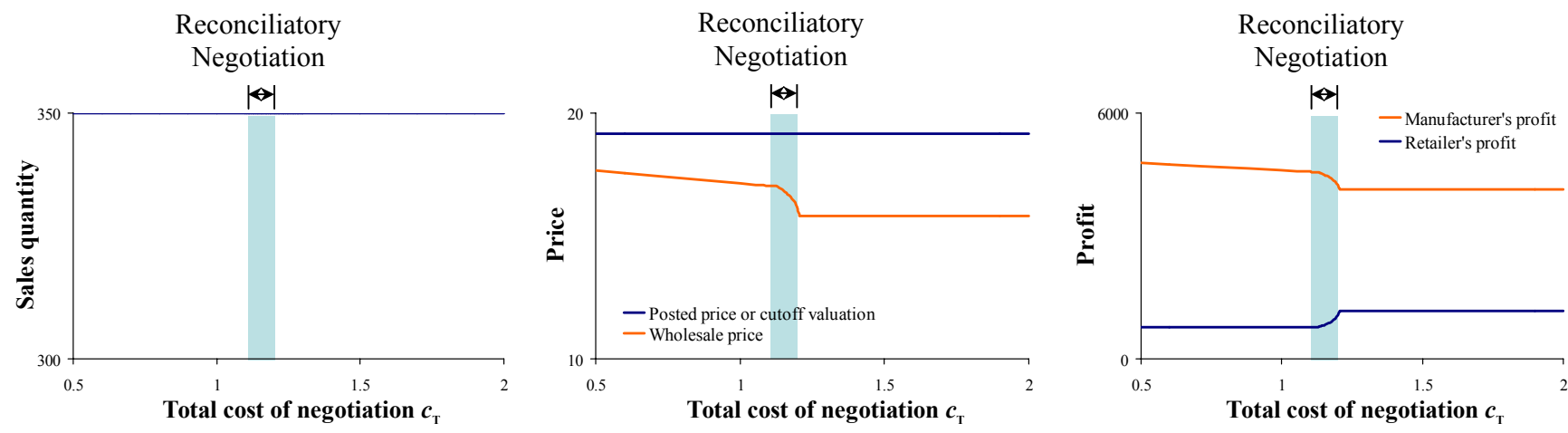
Figure 4 The Figure Illustrates the Sales Quantity (Left), the Wholesale Price (Center), and the Retailer's Profit (Right) in Equilibrium. Here, $a=500, \beta=0.6, c=4, c_{\mathrm{T}}=0.6$, and We Assume Logit Demand with Valuation Distribution $F(x)=\frac{1}{1+e^{20-x}}$

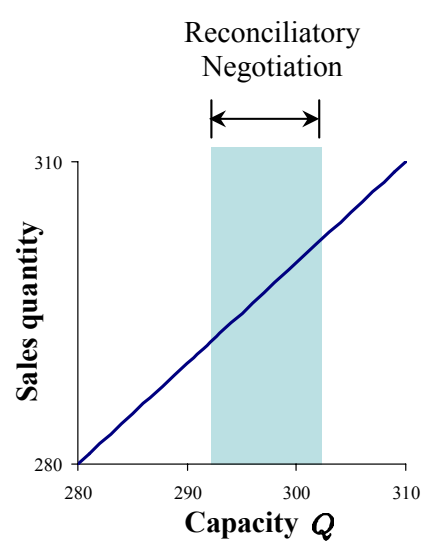

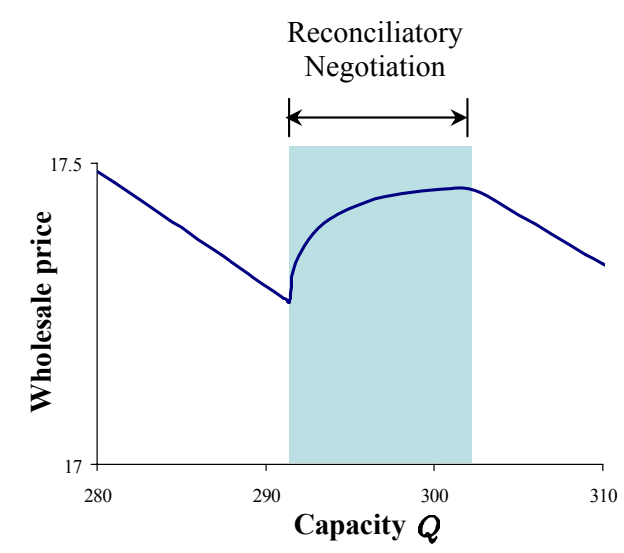

The monotonic behavior of the equilibrium pricing policy with respect to capacity $Q$ and total cost of negotiation $c_{\mathrm{T}}$ gives rise to the following result, which characterizes switching curves that separate different types of equilibria. Figure 5 illustrates three equilibrium regimes separated by two switching curves, which are formally stated in Proposition 9.

Proposition 9. There exist two increasing switching curves, $Q\left(c_{\mathrm{T}}\right)$ and $\bar{Q}\left(c_{\mathrm{T}}\right), \underline{Q}\left(c_{\mathrm{T}}\right) \leq \bar{Q}\left(c_{\mathrm{T}}\right)$, such that the equilibrium is posted pricing if $Q<Q\left(c_{\mathrm{T}}\right)$, reconciliatory negotiation if $Q\left(c_{\mathrm{T}}\right) \leq Q<\bar{Q}\left(c_{\mathrm{T}}\right)$, and ordinary negotiation if $Q \geq \bar{Q}\left(c_{\mathrm{T}}\right)$.

We now examine the effect of disparity in bargaining powers between the retailer and the customer. Figure 6 shows how the equilibrium outcome changes as the customer's relative bargaining power, $\beta$, increases. The behavior of equilibrium is similar to the behavior with respect to the total cost of negotiation, $c_{\mathrm{T}}$ : As the customer's bargaining power $(\beta)$

Figure 5 The Figure Illustrates Three Types of Equilibria: Ordinary Negotiation, Reconciliatory Negotiation, and Posted Pricing. Here, $a=500, \beta=0.6, c=4$, and We Assume Logit Demand with Valuation Distribution $\boldsymbol{F}(\boldsymbol{x})=\frac{1}{1+e^{20-x}}$

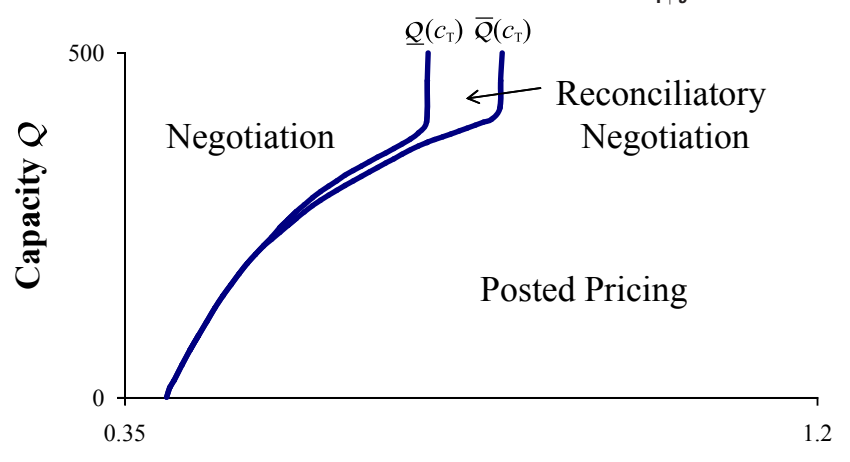

Total cost of negotiation $c_{\mathrm{T}}$ increases, the supply chain's pricing policy toward consumers changes from ordinary negotiation to reconciliatory negotiation to posted pricing. At sufficiently low values of $\beta$, the retailer is able to extract much of the customer surplus, and the supply chain settles in ordinary negotiation. As $\beta$ increases, the retailer's ability to extract customer surplus is hampered, making the retailer more reluctant to negotiate. The manufacturer, on the other hand, is willing to reduce the wholesale price to keep negotiation alive, and the discount is especially sharp at moderate values of $\beta$, resulting in reconciliatory negotiation. Once the depth of the discount needed to induce negotiation becomes too large, the manufacturer gives up on negotiation. The wholesale price then increases and posted pricing becomes the retailer's pricing policy toward consumers. Although we observed this behavior in all of our numerical examples, the highly non-linear dependence of the transaction price (and profit functions) on $\beta$ makes an analytical proof difficult.

The ease with which customers can find out the invoice prices and MSRPs for vehicles is making them more powerful bargainers. This may explain why some dealers like Lithia Motors are turning to posted pricing. It is rather ironic that as informed customers are becoming more eager to negotiate, some dealers shun away from negotiation, which was the gold standard until recent years.

\section{Manufacturer Leadership Model}

In section 4 , we studied a supply chain where the retailer had discretion over pricing policy. We now examine an alternative model in which the manufacturer dictates the supply chain's pricing policy toward consumers along with the wholesale price. The retailer then determines the optimal price associated with the manufacturer-imposed pricing policy: 
Figure 6 The Figure Illustrates the Wholesale Price and Posted Price or Cutoff Valuation (Left) and the Manufacturer's and the Retailer's Profits (Right) in Equilibrium. Here, $a=500, c=4, c_{\mathrm{T}}=0.75, Q=400$, and We Assume Logit Demand with Valuation Distribution $\boldsymbol{F}(\boldsymbol{x})=\frac{1}{1+\boldsymbol{e}^{20-x}}$

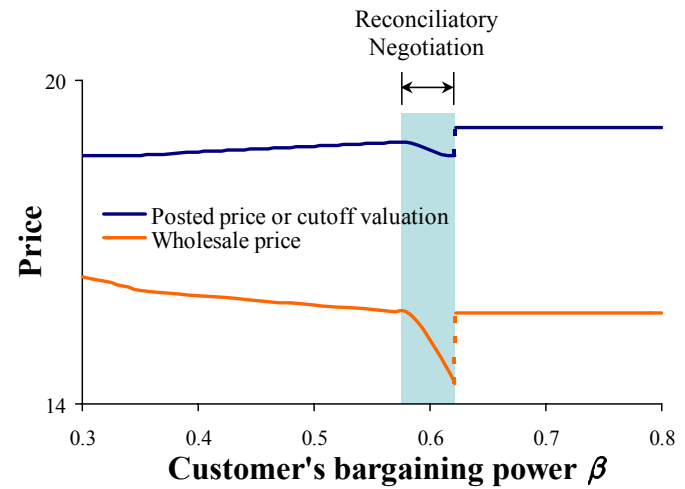

$p^{*}(w, Q)$ under posted pricing and $q_{\min }^{*}(w, Q)$ under negotiation. Examples of this type of relationship are the "no-haggle" pricing policies imposed on Saturn and Scion dealers by GM and Toyota. The manufacturer's problem in this model, stated in Equation (18), can be written as

$$
\begin{array}{r}
\max \left[\max _{w \geq c} \Pi_{\mathrm{MN}}\left(w, q_{\min }^{*}(w, Q), Q\right),\right. \\
\left.\max _{w \geq c} \Pi_{\mathrm{MP}}\left(w, p^{*}(w, Q), Q\right)\right] .
\end{array}
$$

In this case, the choice of the wholesale price is simple. If the manufacturer imposes posted pricing, it will choose $w_{\mathrm{P}}^{*}(Q)$, which maximizes its profit under posted pricing. Likewise, the manufacturer will choose $w_{\mathrm{N}}^{*}(Q)$ when negotiation is imposed. The former leads to the ordinary negotiation regime and the latter leads to the posted pricing regime. In the manufacturer leadership model, the wholesale price that leads to the reconciliatory negotiation regime, $\hat{w}_{R}(Q)$, will never be deployed. Recall that under the reconciliatory negotiation regime, the manufacturer offers a discounted wholesale price due to the retailer's discretion. In the absence of retailer's discretion, the manufacturer need not offer such a discount. Proposition 10 compares the equilibrium pricing policy under two alternative leadership models.

Proposition 10. Given the cost of negotiation, $c_{\mathrm{T}}$, and supply-chain capacity, $Q$ :

(i) If posted pricing is the equilibrium in the manufacturer leadership model, it is also the equilibrium in the discretionary retailer model.

(ii) If ordinary negotiation is the equilibrium in the manufacturer leadership model, it is possible that reconciliatory negotiation or posted pricing is the equilibrium in the discretionary retailer model.

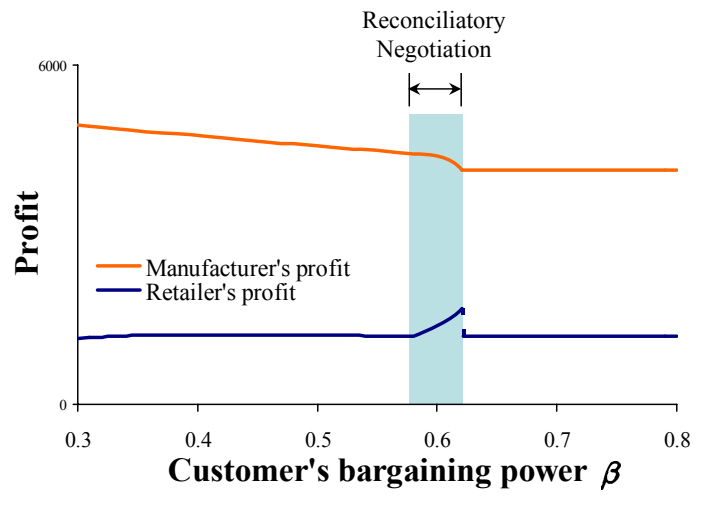

Proposition 10(i) shows that a manufacturer which wishes to impose posted pricing can get its wish even if the retailer has discretion over the pricing policy. On the other hand, a manufacturer who wishes to impose ordinary negotiation may end up with reconciliatory negotiation or posted pricing when faced with a discretionary retailer. As shown in Propositions 7 and 8, when the negotiation cost is low or the capacity is high, even the discretionary retailer chooses ordinary negotiation, and retailer discretion causes no friction. However, as the negotiation cost increases and/or the capacity of the supply chain becomes tighter, the retailer's discretion distorts the equilibrium toward reconciliatory negotiation or posted pricing regime. At such levels of negotiation cost and capacity, the manufacturer who wishes to impose ordinary negotiation has to settle for reconciliatory negotiation or posted pricing in the presence of a discretionary retailer.

Our results suggest that a manufacturer who wishes to impose posted pricing need not implement any monitoring practices beyond setting an appropriate wholesale price. A practical implication is that manufacturers such as GM and Toyota may not have to exert extra effort to sustain the no-haggle policies imposed on Saturn and Scion as long as the wholesale price is set high enough to make the price premium obtained through the negotiation relatively small.

\section{Conclusion}

This article studies the retailer's pricing policy in a supply chain - posted pricing or negotiation. We consider two alternative models of leadership: Either the retailer or the manufacturer determines the pricing policy. Our analysis addresses a number of research questions surrounding the pricing policy choice in a supply chain.

First, we analyze how the manufacturer's wholesale price influences the retailer's preference between 
posted pricing and negotiation. We find that an increase in the wholesale price weakens the retailer's ability to price discriminate through negotiation. Therefore, everything else being equal, negotiation dominates posted pricing at lower wholesale prices, and the opposite is true at higher wholesale prices. This suggests that in the automotive industry, an increase in the wholesale price of a given vehicle, when keeping everything else constant, is likely to popularize "haggle-free" prices.

Second, we analyze which pricing policy the manufacturer prefers the retailer to use. We find that whenever the manufacturer prefers posted pricing, the retailer also prefers posted pricing. One implication is that, in a supply-chain relationship like the one between Toyota and Scion dealers, where Toyota requires that dealers use posted pricing, the manufacturer need not engage in costly monitoring activities to enforce posted pricing as long as the wholesale price is high enough to make the negotiation benefit small.

Third, we ask whether the manufacturer can achieve its desired pricing policy simply by setting an appropriate wholesale price. More precisely, does the manufacturer give up any profits when the retailer chooses the pricing policy? Our answer is yes, but only when the manufacturer prefers negotiation but the retailer does not. In this case, when the manufacturer cannot mandate the retailer's pricing policy toward consumers, the manufacturer either induces the retailer to use negotiation by offering a substantially discounted wholesale price (reconciliatory negotiation) or gives up negotiation and charges a high wholesale price to induce posted pricing. These are the only instances that the manufacturer suffers a loss when it does not have power over pricing policy. For all other cases, the supply-chain profit and its allocations do not depend on who determines the pricing policy. Specifically, when the cost of negotiation is low or the supply-chain capacity is large (both of which enhance the benefit from price discrimination), the manufacturer's and retailer's interests are aligned to use negotiation. Likewise, when the cost of negotiation is high or the capacity is low, both parties' interests are aligned to use posted pricing. For a given product, the capacity and the associated negotiation cost play an important role in determining the chain's pricing policy toward consumers. In light of this, our results support Best Buy's and Home Depot's strategy that allows salespeople to negotiate the prices of select products. On a related note, based on our findings, it is questionable whether Lithia Motors (who sells multiple brands of vehicles ranging from KIA to Porsche) made the right move by switching all of its 108 stores to haggle-free pricing. The rationale for Lithia's decision must go beyond the scope of our model such as competitive pressure (AutoNation advertising its haggle-free prices) and reputation.

Lastly, we analyze how the cost of negotiation and the supply-chain capacity influence the type of equilibrium. In particular, what are the settings for negotiation cost and capacity that will lead to reconciliatory negotiation as an equilibrium outcome? We find that reconciliatory negotiation arises when the capacity or the cost of negotiation is moderate. Thus, only when the capacity or the cost of negotiation is moderate does the the manufacturer suffer a loss for not being able to mandate the retailer's pricing policy toward consumers. Surprisingly, in this region, an increase in negotiation costs or a decrease in capacity could translate to higher profits for the retailer who has power to decide the pricing policy. This counterintuitive phenomenon arises because the retailer's discretion over the pricing policy forces the manufacturer to lower the wholesale price so much that the retailer's profit margin (net of negotiation costs) increases.

We assumed in our analysis that the size of potential consumer population, denoted by $a$, does not depend on the choice of the pricing policy at the retailer level. One could speculate that the size of the population will be smaller under negotiation, maybe because customers who dislike hassles of negotiation will switch to other sellers. Some of this effect is already captured in our model through the cost of negotiation incurred by the customer. In any event, the size of the population simply scales the profit functions without changing their fundamental properties. Therefore, regardless of whether the consumer population is larger or smaller under negotiation, the equilibrium will likely switch from negotiation to reconciliatory negotiation to posted pricing as the cost of negotiation increases or the supply-chain capacity decreases.

We use the GNBS to model the outcome of the negotiation. One limitation of this model is that it ignores the presence of an announced price (e.g., sticker price), which puts a limit on the final transaction price a customer pays. With an announced price, the benefits from negotiation will be smaller, but we expect that our results regarding the three types of equilibrium continue to hold as well as the transition of the equilibrium with respect to the negotiation cost and supply-chain capacity.

Another limitation of GNBS is its implicit assumption that the retailer's and consumers' valuations are common knowledge. In the presence of information asymmetry, there may be instances where the negotiation breaks down even when a consumer values the product more than the seller. GNBS does not capture such situations. Nonetheless, GNBS appears to provide a good compromise between fidelity and tractability. The reasons for this assessment are twofold. 
First, while information asymmetry can lead to cases where a deal breaks down, the transaction price that arises under GNBS could still be a good proxy for the equilibrium price that would arise whenever a deal is struck under information asymmetry: For example, Cramton (1992) considers a bargaining game where parties make sequential offers after a strategically chosen delay and constructs an equilibrium such that the trade occurs at the price that would prevail if there were no information asymmetry. Second, and perhaps more importantly, the equilibrium outcomes predicted by GNBS received considerable support from behavioral research. If one wants to step away from GNBS to look for alternative means that can capture information asymmetry, the remaining natural choice would be a non-cooperative game-theoretic model of bargaining. However, there is sufficient experimental evidence to suggest that such non-cooperative solutions are no better than GNBS in predicting the outcomes of actual bargaining situations (see Chapter 4 in Kagel and Roth 1995 and Chapter 5 in Davis and Holt 1992).

Our model assumes that no negotiation cost is incurred in those cases where the customer's reservation price is so low that the retailer and the customer do not trade. This is in keeping with the Nash bargaining solution, which posits that the parties would never initiate negotiation if it is bound to fail. Nonetheless, relaxing this assumption does not change our insights at all. To examine this, we consider two modified versions of this model. In the first version of the model, all customers negotiate with the retailer, no matter what their reservation price is, and the retailer incurs its cost of negotiation, $c_{r}$, for all customers. In the second version of the model, we assume that the retailer negotiates only with customers whose reservation price $r$ exceeds their negotiation $\cos t c_{b}$. Some of these customers will still end up not purchasing (those whose reservation price $r$ falls below $q_{\min }$ ), but the retailer will incur the negotiation $\operatorname{cost} c_{r}$ even for those customers. Under both of these two models, our analytical and numerical results suggest that our insights regarding the equilibrium behavior continue to hold.

Our model assumes that the supply chain commits to one pricing policy for a given product. In some cases, two pricing policies could coexist: selling at the posted price to some customers while negotiating with other customers. This hybrid pricing policy is more pronounced when there are multiple types of customers differentiated by their bargaining power. The supply chain's pricing policy choice (posted pricing, mixed, or negotiation) in the presence of the multi-segmented consumer population merits further research.

We focused on a simple wholesale price contract in this article. Although it is difficult to incorporate fur- ther contract terms into our analysis, our results and insights enable us to conjecture about how the equilibrium might change as we change the contractual terms. We note that the retailer prefers negotiation when the wholesale price is low enough that the retailer's margin leaves enough room to price discriminate among customers. Given this observation, we expect that any contractual arrangement that lowers the retailer's unit cost for the product will provide the retailer further incentive to adopt negotiation. Consequently, we expect that enriching the contractual arrangement to include quantity discounts or channel rebates will increase the likelihood of negotiation emerging in equilibrium. On the other hand, we expect that any contractual change that increases the retailer's unit cost will induce the retailer to deploy posted pricing.

There are certain strategic considerations that we left out of our model. For example, some retailers may opt for negotiation to accommodate bargainhunting customer segments that emerge in a tough economic climate. Other retailers may opt for posted pricing to carve a niche in a market primarily dominated by retailers that haggle. Furthermore, if a manufacturer is selling through many dealers, the manufacturer may try to enforce posted pricing to maintain pricing consistency across its dealer network. Our model does not explicitly consider the effect of these factors on the choice between posted pricing and negotiation. However, we show that, even when none of these more strategic concerns is present, supply-chain conflict may arise in the choice of the pricing policy. How that conflict is further shaped by the presence of strategic considerations such as competition, bargain-hunting consumers, or multiple sales channels is open to further research.

\section{Notes}

${ }^{1}$ Sources: http://www.trackerboats.com/about/no-hasslepricing.cfm, http://www.crystalpierz.com/no-haggle-nohassle.htm. Last retrieved: July 3, 2012.

${ }^{2}$ In particular, Equation (1) guarantees that the retailer's best responses are increasing and convex with respect to the wholesale price under both pricing policies.

${ }^{3}$ When the supply-chain capacity $Q$ is so large that $\bar{p}(Q)$ does not exist, we use the convention that $\bar{p}(Q)=-\infty$.

${ }^{4}$ If $Q$ is sufficiently large, it may not be possible for the manufacturer to profitably induce the retailer to sell $Q$ units. In other words, there may not exist $\bar{w}_{\mathrm{P}}(Q)>c$ for sufficiently large $Q$, in which case we follow the convention of setting $\bar{w}_{\mathrm{P}}(Q)=-\infty$.

${ }^{5} \mathrm{We}$ include the capacity $Q$ in the list of arguments for the functions $\Pi_{R N}$ and $\Pi_{\mathrm{MN}}$ because the optimal values of these functions will depend on $Q$. The dependence arises because the retailer's optimal cutoff valuation $q_{\min }$ must be at least as large as the market-clearing price $\bar{p}(Q)$, which is of course a function of the capacity $Q$. 
${ }^{6}$ There may not exist $\bar{w}_{\mathrm{N}}(Q)>c$ for sufficiently large $Q$, in which case we follow the convention of setting $\bar{w}_{\mathrm{N}}(Q)=-\infty$.

${ }^{7}$ One could consider a variation of the discretionary retailer model where the retailer's pricing policy choice precedes the manufacturer's wholesale price decision. We exclude this possibility, as it is not a very credible sequence of events: The retailer would have little reason to commit to a pricing policy before observing the wholesale price.

${ }^{8}$ Note that Proposition 4 includes two special cases: (i) The retailer prefers posted pricing for all feasible wholesale prices $w \geq c$ and (ii) the retailer prefers negotiation for all feasible wholesale prices $w \geq c$.

${ }^{9}$ This intuitive result is established by Lemma A.2(b) in the Appendix, which states that $q_{\min }^{u}(w)$ is increasing in $w$ and $q_{\min }^{*}(w, Q)=\max \left\{q_{\min }^{u}(w), \bar{p}(Q)\right\}$.

${ }^{10}$ In Figure 3 , no matter what the equilibrium pricing policy is, the sales quantity is bounded by the supplychain capacity. We should note, however, that at $c_{\mathrm{T}}$ values where negotiation is the equilibrium, if the manufacturer switched to posted pricing, the sales quantity would be lower than that obtained under negotiation. This is because the manufacturer would have to charge a much higher wholesale price to induce posted pricing, thereby reducing the sales quantity below capacity.

${ }^{11}$ Sources: http://en.wikipedia.org/wiki/Lexus_LS\#Sales_ and_production, http://en.wikipedia.org/wiki/Lexus_SC\# Sales_and_production. Last retrieved: July 3, 2012.

${ }^{12}$ Source: http://money.cnn.com/2006/11/06/autos/prius / - "Wait time for Prius buyers diminishing. Shortage of popular gas-electric cars eases while demand cools, report says." Last retrieved: July 3, 2012.

${ }^{13}$ Source: http:/ / www.carsdirect.com.

\section{References}

Adachi, M. M. 1999. On the choice of pricing policies: Ex ante commitment and prisoners' dilemma. Eur. Econ. Rev. 43(9): 1647-1663.

Arnold, M. A., S. A. Lippman. 1998. Posted prices versus bargaining in markets with asymmetric information. Econ. Inq. 36(3): 450-457.

Bester, H. 1993. Bargaining versus price competition in markets with quality uncertainty. Am. Econ. Rev. 83(1): 278-288.

Cramton, P. C. 1992. Strategic delay in bargaining with two-sided uncertainty. Rev. Econ. Stud. 59(1): 205-225.

Davis, D., C. Holt. 1992. Experimental Economics. Princeton University Press, Princeton, NJ.

Desai, P., D. Purohit. 2004. "Let me talk to my manager": Haggling in a competitive environment. Market. Sci. 23(2): 219-233.

Dreze, X., D. R. Bell. 2003. Creating win-win trade promotions: Theory and empirical analysis of scan-back trade deals. Market. Sci. 22(1): 16-39.
Dukes, A., E. Gal-Or. 2003. Negotiations and exclusivity contracts for advertising. Market. Sci. 22(2): 222-245.

Gurnani, H., M. Shi. 2006. A bargaining model for a first-time interaction under asymmetric beliefs of supply reliability. Manage. Sci. 52(6): 865-880.

Iyer, G., J. M. Villas-Boas. 2003. A bargaining theory of distribution channels. J. Mark. Res. 40(1): 80-100.

Kagel, J., A. Roth. 1995. Handbook of Experimental Economics. Princeton University Press, Princeton, NJ.

LaBarre, K. 2011. Fiat pledges no-haggle pricing at U.S. dealerships. US News \& World Report (January 31).

Lal, R., J. D. C. Little, J. M. Villas-Boas. 1996. A theory of forward buying, merchandising and trade deals. Market. Sci. 15(1): 2137.

Let's make a deal. The Economist. February 2009, p. 57

Lovejoy, W. S. 2007. Bargaining chains. Working paper, Ross School of Business, University of Michigan, Ann Arbor, MI.

Muthoo, A. 1999. Bargaining Theory with Applications. Cambridge University Press, Cambridge, UK.

Nagarajan, M., Y. Bassok. 2008. A bargaining framework in supply chains (The assembly problem). Manage. Sci. 54(8): 14821496.

Nagarajan, M., G. Sosic. 2008. Game-theoretic analysis of cooperation among supply chain agents: Review and extensions. Eur. J. Oper. Res. 187(3): 719-745.

Richtel, M. 2008. Even at megastores, hagglers find no price is set in stone. The New York Times (March 23). Last retrieved on September 27, 2012 from http://www.nytimes.com/2008/03/ 23/business/23haggle.html

Riley, J., R. Zeckhauser. 1983. Optimal selling strategies: When to haggle, when to hold firm. Q. J. Econ. 98(2): 267-289.

Roth, S., H. Woratschek, S. Pastowski. 2006. Negotiating prices for customized services. J. Serv. Res. 8(4): 316-329.

Wang, R. 1995. Bargaining versus posted-price selling. Eur. Econ. Rev. 39(9): 1747-1764.

Welch, D. 2007. Haggling starts to go the way of the tail fin. Business Week (Oct. 29): 71.

Wu, D. 2004. Supply chain intermediation: A bargaining theoretic framework. D. Simchi-Levi, ed. Handbook of Quantitative Supply Chain Analysis: Modeling in the E-business Era. Kluwer Academic Publishers, Boston, 67-115.

\section{Supporting Information}

Additional Supporting Information may be found in the online version of this article:

Appendix S1: Proofs of Propositions.

Appendix S2: Proofs of Propositions.

Please note: Wiley-Blackwell are not responsible for the content or functionality of any supporting materials supplied by the authors. Any queries (other than missing material) should be directed to the corresponding author for the article. 